\title{
PENGEMBANGAN TERMOMETER GAS SEBAGAI ALAT PERAGA PEMBELAJARAN POKOK BAHASAN SKALA SUHU MUTLAK
}

Tugiyo Aminoto ${ }^{1}$, Rahma Dani ${ }^{2}$, Edi Yuversa ${ }^{3}$

${ }_{1,2,3}$ Pendidikan Fisika, Universitas Jambi, Indonesia

Email: tugiyo@unja.ac.id, radanicev@yahoo.com, ediyuversa88@gmail.com

Info Artikel

Diterima:

13 September 2019

Disetujui:

29 November 2019

Dipublikasikan:

15 Desember 2019

\begin{abstract}
Abstrak:
Alat peraga termometer gas tipe volume konstan memiliki peran penting sebagai media pembelajaran yang dapat membantu para mahasiswa agar dapat memahami konsep suhu mutlak secara lebih mudah dan konkrit. Mengingat alat ini sulit dijumpai di pasaran maka sangat perlu dilakukan usaha untuk membuat dan mengembangkan alat tersebut. Tujuan penelitian pengembangan ini adalah untuk menghasilkan produk berupa alat peraga termometer gas tipe volume tetap yang lebih baik dari yang ada. Metode penelitian yang digunakan adalah penelitian pengembangan yang meliputi penelitian dan pengumpulan data, perencanaan, pengembangan draf produk, pengembangan bahan pembelajaran, proses pembelajaran, dan instrumen evaluasi, uji coba lapangan awal, uji coba lapangan, penyempurnaan produk hasil uji lapangan, penyempurnaan produk akhir dan implementasi.
\end{abstract}

Kata kunci: Alat peraga, termometer gas, penelitian pengembangan

\begin{abstract}
:
The constant volume type gas thermometer has an important role as a learning medium that can help students understand the concept of absolute temperature more easily and concretely. Considering that this tool is difficult to find in the market, it is necessary to make an effort to make and develop the tool. The purpose of this development research is to produce a product in the form of a fixed volume type gas thermometer that is better than the existing one. The research method used is research development that includes research and data collection, planning, developing product drafts, developing learning materials, learning processes, and evaluation instruments, initial field trials, field trials, refining product field test results, perfecting final products and implementation.
\end{abstract}

Keywords: Visual aids, gas thermometer, research development 


\section{Pendahuluan}

Di kalangan peserta didik banyak berkembang kesan yang kuat bahwa pelajaran fisika merupakan pelajaran yang sulit untuk dipahami dan kurang menarik (Betha, 2004). Hal ini disebabkan kurangnya minat dan motivasi untuk mempelajari fisika dengan senang hati, sehinga banyak siswa merasa kurang tertarik untuk mempelajari fisika. Hal ini ternyata terjadi sampai pada tingkat yang lebih tinggi yakni Universitas.

Lemahnya motivasi belajar fisika karena kurangnya pemahaman tentang hakikat, kemanfaatan, keindahan dan lapangan kerja yang dapat dihasilkan dari belajar fisika. Agar belajar fisika terasa lebih menyenangkan, maka manfaat belajar fisika perlu dipahami. Untuk menghadapi halangan atau kesulitan apapun ketika sedang belajar fisika motivasi belajar menjadi modal pertama.

Belajar yang sebenarnya adalah lebih dari sekadar proses menghafal dan menumpuk ilmu pengetahuan, tetapi juga bagaimana pengetahuan yang diperoleh mahasiswa bermakna melalui keterampilan berpikir. Untuk dapat menjadikan belajar lebih termotivasi maka diperlukan sekali media belajar yang mampu menarik minat mahasiswa untuk belajar. Melalui penggunaan alat peraga, hal-hal yang abstrak dapat disajikan dalam bentuk konkrit yang dapat dilihat, dipegang, dicoba sehingga dapat dengan mudah dipahami oleh siswa. Fungsi utama alat peraga itu sendiri adalah untuk menurunkan keabstrakan konsep yang diberikan oleh guru agar siswa mampu menangkap arti dari konsep abstrak tersebut dengan mudah menggunakan alat peraga. Sejalan dengan Wijaya dan Rusyan (1994) yang menyatakan bahwa alat peraga pendidikan berperan sebagai perangsang belajar dan dapat menumbuhkan motivasi belajar sehingga siswa tidak menjadi bosan dalam meraih tujuan-tujuan belajar.

Salah satu topik penting dari ilmu fisika adalah termodinamika. Hal ini karena pemanfaatanya yang sangat nyata dalam kehidupan sehari-hari. Tanpa mempelajari termodinamika, mahasiswa akan sangar sulit memahami proses pendinginan ruangan dengan mesin AC, makanan dapat bertahan lama jika disimpan di lemari pendingin, sampai ke beberapa teknologi yang menggunakan prinsip mesin kalor, seperti motor bensin dan diesel dan lainnya. Ini membuktikan bahwa belajar termodinamika menjadi modal utama dalam menghadapi tantangan zaman.

Dari studi pendahuluan, ketersediaan alat lab ataupun alat peraga termometer gas laboratorium fisika di PT dan di SMA adalah sangat minim. Salah satu media pembelajaran yang sangat penting digunakan dalam sebuah percobaan yang berhubungan dengan mata kuliah termodinamika ialah termometer gas yang merupakan termometer standar untuk mengkalibrasi termometer jenis lainnya. Termometer ini menggunakan prinsip pemuaian gas bervolume $\mathrm{V}$ memuai dan memiliki tekanan $\mathrm{P}$ sehingga sangat terkait dengan persamaan gas ideal $\mathrm{PV}=\mathrm{nRT}$. Dalam rumus terkenal tersebut tampak sekali bagaimana tekanan dan volume gas berkaitan langsung dengan suhu T. Mengingat bahwa pemuaian pada gas adalah berlangsung lebih halus maka termometer gas sangat cocok dijadikan sebagai termometer standar yang juga berguna untuk mengkalibrasi termometer jenis lainnya.

Tidak tersedianya alat peraga termometer gas untuk memudahkan mahasiswa memahami konsep pendefinisian suhu mutlak termometer gas tersebut dan tidak mudah ditemukannya alat tersebut di pasaran maka sangat diperlukan upaya untuk membuat sendiri alat tersebut mengingat alat peraga tersebut sangat penting sekali dalam perkuliahan termodinamika. Berdasarkan latar belakang masalah di atas maka rumusan masalah dalam penelitian ini adalah bagaimana mengembangkan dan menghasilkan termometer gas yang dapat digunakan sebagai alat peraga pembelajaran pada pokok bahasan skala suhu mutlak pada mata kuliah termodinamika.

Adapun tujuan dari penelitian ini adalah mengembangkan alat termometer gas sebagai alat peraga pembelajaran pokok bahasan skala suhu mutlak pada mata kuliah termodinamika. Penelitian ini dapat bermanfaat untuk media pembelajaran yang dapat dimanfaatkan untuk menunjang kegiatan pembelajaran di kelas dan percobaan atau penelitian di laboratorium fisika.

\section{Metode Penelitian}

Penelitian ini merupakan jenis penelitian dan pengembangan atau Research and Development (R\&D). Menurut Sugiyono (2012) penelitian dan pengembangan adalah metode 
penelitian yang digunakan untuk menghasilkan produk tertentu, dan menguji keefektifan produk tersebut. Sukmadinata (2006) mendefinisikan penelitian dan pengembangan merupakan pendekatan penelitian untuk menghasilkan produk baru atau menyempurnakan produk yang telah ada. Jadi penelitian pengembangan merupakan metode untuk menghasilkan produk tertentu atau menyempurnakan produk yang telah ada serta menguji keefektifan produk tersebut. Peneliti melakukan penelitian dan pengembangan alat peraga pada pokok bahasan pengukuran suhu pada mata kuliah termodinamika. Untuk mendapatkan hasil yang maksimal maka pengembangan alat peraga ini di validasi oleh ahli materi dan ahli media serta diuji coba penggunaan oleh dosen dan mahsiswa.

Penerapan langkah-langkah pengembangannya disesuaikan dengan kebutuhan peneliti. Mengingat keterbatasan waktu dan dana maka langkah-langkah tersebut disederhana-kan menjadi empat langkah pengembangan. Langkah pengembangan yang dilakukan oleh peneliti adalah:

1. Tahap pengumpulan data

Tahap pengumpulan data dilakukan untuk mengetahui kebutuhan pembelajaran di lapangan. Tahap pengumpulan data dilakukan dengan cara studi lapangan dan studi pustaka.

a. Studi lapangan dilakukan untuk mengetahui kebutuhan sumber belajar di perkuliahan mata kuliah termodinamika. Hal ini dilakukan dengan cara analisis kurikulum yang berlaku, analisis tahap perkem-bangan mahasiswa, dan analisis ketersediaan sumber belajar di kelas dan di lab fisika.

b. Studi pustaka mengenai teori yang berhubungan dengan media pembelajaran termometer gas.

2. Tahap perencanaan

Tahap perencanaan dilaku-kan dengan koordinasi tim peneliti dalam perancangan alat peraga. Kemudian tim menentukan desain dan kebutuhan alat dan bahan dalam pembuatan media pembelajaran yang dibutuhkan.

3. Tahap pengembangan produk

Tahap pengembangan pro-duk dimulai dengan pengumpulan bahan, pengelolaan bahan, dan terakhir adalah produksi.
4. Tahap validasi dan uji coba

Media pembelajaran yang telah diproduksi kemudian di-evaluasi. Teknik evaluasi produk dilakukan dengan proses validasi dari tim ahli. Validasi dilakukan dalam dua tahap. Tahap I adalah validasi oleh ahli materi dan ahli media. Melalui tahap ini diperoleh data kelayakan produk dan saran dari para ahli. Saran tersebut kemudian digunakan untuk revisi produk tahap I. Hasil revisi tahap I digunakan untuk validasi ke II oleh dosen, saran dari dosen digunakan untuk revisi II. Hasil dari kedua revisi tersebut digunakan untuk uji coba penggunaan oleh mahasiswa. Hasil uji coba ini berupa tanggapan mahasiswa terhadap media pembelajaran yang dibuat tersebut.

\section{Hasil Penelitian dan Pembahasan}

Tahap pengumpulan data dilakukan untuk mengetahui aspek kebutuhan yang diperlukan untuk meningkatkan kualitas pembelajaran matakuliah termodinamika. Tahap pengumpulan data dilakukan dengan cara studi lapangan dan studi pustaka. Studi lapangan dilakukan untuk mengetahui kebutuhan sumber belajar di perkuliahan matakuliah termodinamika. Hal ini dilakukan dengan cara analisis kurikulum, analisis tahap perkembangan mahasiswa, dan analisis ketersediaan sumber belajar di kelas dan di lab fisika. Studi pustaka dilakukan mengenai teori yang berhubungan dengan media pembelajaran termometer gas.

Hasil analisis kurikulum menghasilkan kesimpulan bahwa konsep skala mutlak didasarkan pada penemuan titik suhu terendah di alam ini dan skala mutlak ini telah ditetapkan menjadi skala suhu standar internasional dalam pengukuran temperatur. Penetapan skala mutlak ini (Kelvin) karena pada skala ini titik batas atau titik acuannya diperoleh dari eksperimen bukan karena hasil penetapan skala secara relatif (atas dasar mencari kemudahan) sebagaimana skala yang lain (Fahrenheit, Reamur dan Celcius). Jadi, pemahaman mahasiwa terhadap konsep skala suhu mutlak ini sangat penting sehingga diperlukan usaha meningkatkan kualitas media pembelajaran yang semakin mem-permudah dan mempercepat pemahaman mahasiswa. 
Analisis tahap perkembangan mahasiswa dilakukan dengan angket analisis kebutuhan mahasiswa dan menghasilkan kesimpulan bahwa mahasiswa peserta matakuliah termodinamika memiliki hasil belajar yang kurang dan faktor penyebab diantaranya adalah rendahnya motivasi belajar akibat perkuliahan yang tidak menarik dan tidak didukung dengan media pembelajaran yang baik dan lengkap.

Hasil analisis ketersediaan sumber belajar di kelas dan di lab pada prodi pendidikan fisika Universitas Jambi juga dilakukan dan hasilnya adalah media pembelajaran yang terkait dengan matakuliah termodinamika sangat minim. Hal ini karena proporsi kegiatan percobaan fisika untuk memperdalam konsep ilmu fisika hanya difokuskan pada matakuliah fisika dasar dan elektronika sedangkan untuk matakuliah diatas dasar (lanjut) belum mampu dimaksimalkan karena keterbatasan sarana.

Tahap perencanaan dilakukan dengan koordinasi tim peneliti dalam perancangan alat peraga. Kemudian tim menentukan desain dan kebutuhan alat dan bahan dalam pembuatan media pembelajaran yang dibutuhkan. Termomter gas menggunakan prinsip pengaruh suhu terhadap pemuaian gas. Bagan alat ini sama seperti nanometer. Pipa U yang berisi raksa mula-mula permukaannya sama tinggi. Jika salah satu ujungnya dihubungkan dengan ruangan yang bersisi gas bertekanan, maka akan terjadi selisih tinggi. Salah satu versi termometer gas yang merupakan peralatan dengan volume konstan ditunjukkan pada Gambar 1. Perubahan fisik yang dimanfaatkan dalam perangkat ini adalah perubahan tekanan akibat volume tetap gas terhadap suhu.

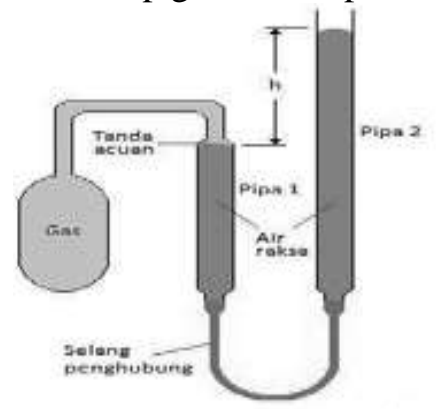

Gambar 1. Skema termometer gas

Labu berisi gas tersebut kemudian dikenakan pada objek yang akan diukur. Pipa/tandon pipa 2 dinaik-turunkan sampai batas merkuri di kolom pipa 1 tepat pada skala nol, yang menjamin bahwa volume gas adalah sama seperti ketika labu pada keadaan awalnya (volume gas di jaga tetap). Termometer gas jenis ini disebut termometer gas volume tetap sedangkan. Tipe kedua dari termometer gas ini adalah apabila volume berubah dan tekanannya yang dijaga konstan, namun tidak praktis dipakai karena tingkat kesalahannya besar. Adapun persamaan yang berlaku pada termometer gas volume tetap adalah (Zemansky \& Dittmann, 1982):

$T=273,16 \lim _{P_{T P}} \frac{P}{P_{T P}}$

$($ satuan $K)$

Untuk mendapatkan titik yang menyatakan suhu terendah di alam semesta atau titik nol mutlak $(\mathrm{T}=0 \mathrm{~K})$ maka dilakukan pengukuran minimal pada dua titik, misalnya pada titik beku air (labu berisi gas direndamkan dalam es mencair) dan titik uap air (labu berisi gas direndamkan dalam air mendidih). Pada dua titik itu diukur tekanan gas dari ketinggian air raksa dengan persamaan $\mathrm{P}=\mathrm{P}_{0}+\rho g h$.

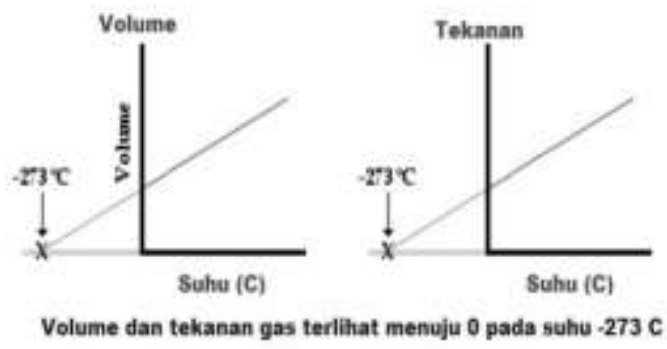

Gambar 2. Ekstrapolasi pada grafik $\mathrm{P}$ versus T untuk mendapatkan titik -273 C

Percobaan menunjukkan bahwa pembacaan termometer hampir independen dari jenis gas yang digunakan selama tekanan gas rendah dan suhu jauh di atas titik di mana gas mencair. Percobaan menggunakan jenis gas yang berbeda akan menghasilkan titik potong yang sama pada sumbu $\mathrm{X}$ tetapi hanya berbeda kemiringannya. 


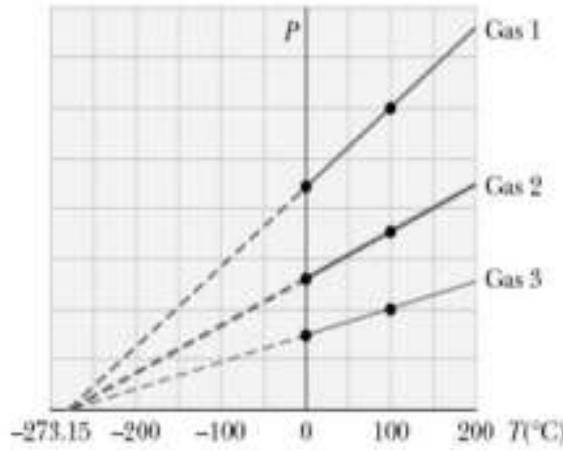

Gambar 3. Penggunaan gas yang berbeda menghasilkan titik potong yang sama pada sumbu X

Jika garis diperpanajang (ekstrapolasi) pada Gamba terhadap suhu negatif maka akan ditemukan hasil yang luar biasa: dalam setiap kasus, tekanan adalah nol saat suhu $-273.15^{\circ} \mathrm{C}$. Temuan ini menunjukkan bahwa ada titik yang menunujkan temperatur terendah di alam ini. Hal ini digunakan sebagai dasar untuk skala temperatur absolut, yang menetapkan $-273.15^{\circ} \mathrm{C}$ sebagai suhu terendah (titik nol). Suhu ini sering disebut sebagai titik nol mutlak (absolute zero). Hal ini dianggap sebagai nol karena pada suhu yang lebih rendah, tekanan gas menjadi negatif (yang tidak memilik arti). Ukuran satu derajat pada skala temperatur absolut dipilih sama dengan ukuran satu derajat pada skala Celcius dan konversi antara 2 sakala suhu ini adalah:

$$
\mathrm{T}_{\mathrm{C}}=\mathrm{T}-273,15
$$

dimana $\mathrm{T}_{\mathrm{C}}$ adalah suhu dalam skala Celsius dan $\mathrm{T}$ adalah suhu absolut.

Karena titik es dan uap eksperimental sulit ditiru dan tergantung pada tekanan atmosfer, skala temperatur absolut didasarkan pada dua titik tetap yang baru yang dilakukan tahun 1954 oleh the International Committee on Weights and Measures (Komite Internasional tentang Berat dan Ukuran). Titik bawah/pertama adalah nol mutlak. Kedua temperatur referensi bagi skala ini baru terpilih sebagai triple point dari air, yang merupakan kombinasi tunggal suhu dan tekanan di mana air cairan, air gas, dan es (air zat padat) berada bersamaan dalam keseimbangan. Titik tripel ini terjadi pada suhu $0.01^{\circ} \mathrm{C}$ dan tekanan $4,58 \mathrm{mmHg}$. Pada skala yang baru, menggunakan satuan kelvin, suhu air pada titik triple ditetapkan sebesar 273,16 kelvin, disingkat 273,16 K
Tabel 3. aspek pengembangan yang dilakukan

\begin{tabular}{lll}
\hline No & $\begin{array}{l}\text { Alat yang } \\
\text { sudah ada }\end{array}$ & $\begin{array}{c}\text { Alat yang } \\
\text { dikembangkan }\end{array}$ \\
\hline 1 & $\begin{array}{l}\text { Belum } \\
\text { tersedia di lab } \\
\text { dan belum di } \\
\text { kalibrasi }\end{array}$ & Bisa dikalibrasi \\
& & \\
\end{tabular}

\begin{tabular}{lll}
\hline 2 & Panjang & Diperpanjang hingga \\
skalanya & $100 \mathrm{~cm}$ sehingga dapat \\
hanya $50 \mathrm{~cm}$ & $\begin{array}{l}\text { digunakan pada suhu } \\
\text { yang lebih tinggi. }\end{array}$
\end{tabular}

Diikuti dengan pemanjangan selang dan pembuatan lubang sehingga selang/pipa $\mathrm{U}$ dapat dimasukan ke dalam lubang tersebut dan akan memudahkan saat pipa $B$ harus dinaik-turunkan sesuai kebutuhan

3 Tidak Labu kaca
memungkinka dimodifikasi sehingga n mengganti ada 2 kran di kanan jenis gasnya dan kirinya sehingga penggantian gas dengan jenis lain bisa dilakukan

4 Pamanasan Pamanasan sampel air sampel air dengan pemanas listrik tidak sehingga lebih praktis disebutkan

\begin{tabular}{lll}
\hline 5 & $\begin{array}{l}\text { Tidak mudah } \\
\text { dipindahkan }\end{array}$ & $\begin{array}{l}\text { Diberi alas dari kayu } \\
\text { dan beroda sehingga } \\
\text { mudah dipindahkan } \\
\text { (mobile) }\end{array}$ \\
\hline
\end{tabular}

Berdasarkan model termometer gas yang sudah ada maka dilakukan analisis kebutuhan dengan mempertimbangkan beberapa aspek yang bisa dikembangkan agar memberikan kemudahan dan hasil ukur yang lebih teliti. Selanjutnya dibuat gambar desain alat setelah dilakukan percobaan dan menganalisis kelemahan-kelamahan alat maka dilakukan desain pengembangan (gambar a) dan implementasi pada beberapa aspek pengembangan di atas dihasilkan alat termometer gas sebagai berikut (gambar b): 

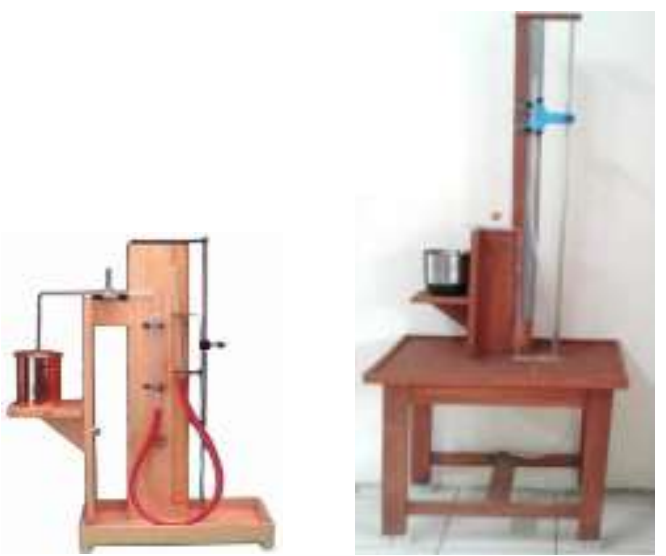

Gambar 4. (a) Alat yang ada di pasaran (b) Alat hasil pengembangan

Untuk percobaan pengukuran menggunakan termometer gas (yang telah dikembangkan) dilakukan (untuk tahap 1) dengan menggunakan gas biasa (udara dalam ruangan lab) dan cairan pengisi selang juga mengunakan air biasa (air murni/aquades hasil penyulingan). Pengambilan data dilakukan sebanyak tiga kali dengan berusaha seteliti mungkin (dan meminimalisir errornya) dengan prosedur sebagai berikut:

1. Menyiapkan alat thermometer gas

2. Memastikan ketinggian awal cairan di pipa $U$ adalah sama tingginya (Jika tidak sama tinggi maka buka penutup gas dan tutup lagi jika tingginya sudah sama)

3. Mencatat ketinggian awal tersebut

4. Menghidupkan pemanas listrik pada gelas ukur

5. Memperhatikan bahwa gas akan memuai dan mendorong cairan pada pipa $B$ ke atas sampai ketinggian tertentu.

6. Pada saat ketinggian cairan tidak naik lagi maka pipa B digeser naik hingga ketinggian pipa A kembali ke ketinggian semula.

7. Mencatat ketinggian cairan di pipa $B$

8. Melakukan langkah yang sama untuk air dengan suhu yang berbeda

Adapun hasil percobaan dan pengambilan data yang telah dilakukan disajikan dalam tabel berikut :
Tabel 4. Data hasil percobaan

\begin{tabular}{ccccc}
\hline $\mathrm{T}$ & $\begin{array}{c}\mathrm{h} 1 \\
(\mathrm{~cm})\end{array}$ & $\begin{array}{c}\mathrm{h} 0 \\
(\mathrm{~cm})\end{array}$ & $\begin{array}{c}\Delta \mathrm{h} \\
(\mathrm{m})\end{array}$ & $\mathrm{P}$ \\
\hline 46 & 59 & 5.8 & 0.532 & $1.06 \mathrm{E}+05$ \\
44 & 53 & 5.8 & 0.472 & $1.06 \mathrm{E}+05$ \\
41 & 46 & 5.8 & 0.402 & $1.05 \mathrm{E}+05$ \\
40 & 43 & 5.8 & 0.372 & $1.05 \mathrm{E}+05$ \\
39 & 40 & 5.8 & 0.342 & $1.04 \mathrm{E}+05$ \\
37 & 36 & 5.8 & 0.302 & $1.04 \mathrm{E}+05$ \\
34.5 & 26.5 & 5.8 & 0.207 & $1.03 \mathrm{E}+05$ \\
\hline
\end{tabular}

Selanjutnya data tersebut dijadikan grafik dengan Excel sebagai berikut:

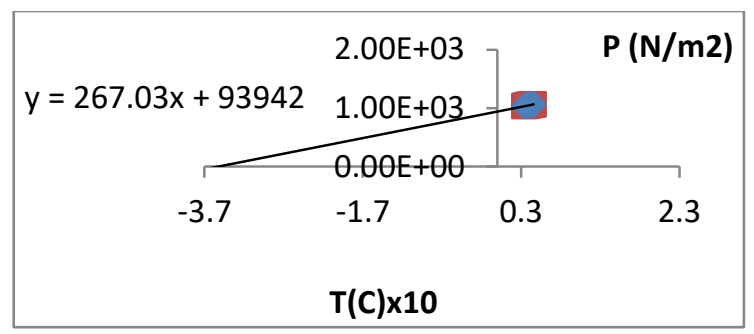

Gambar 6. Grafik hasil percobaan

Jika diamati dari hasil grafik di atas maka titik potong pada sumbu $\mathrm{x}$ terjadi pada $-351,8$. Untuk mendapatkan nilai pada titik potong grafik bisa diperoleh dari persamaan garisnya yaitu dengan memasukan nilai $\mathrm{y}=0$ sebagai berikut:

$$
\begin{aligned}
& y=267,03 x+93942 \\
& 0=267,03 x+93942 \\
& -267,03 x=93942 \\
& x=-93942 / 267,03 \\
& x=-351,8
\end{aligned}
$$

Hasil ini masih agak jauh dari nilai standar internasionalnya yaitu $-273,15$. Tidak diperolehnya hasil ukur yang sama dengan nilai standarnya tersebut kemungkinan masih ada kebocoran gas pada sambungan tabung kaca, kebocoran panas pada pipa kaca dan belum digunakannya gas yang mendekati sifat gas ideal (Helium) sehingga hasil ekstrapolasi yang peroleh masih jauh dari literatur (eksperimen ini sangan membutuhkan kondisi yang sangat ideal).

Dari hasil validasi tim ahli diperoleh saran-saran: pertama, agar pemasangan mistar mulai dari bawah (menyentuh meja) agar dapat mengukur secara teliti ketinggian cairan meskipun pada kondisi ketinggian cairan sangat dekat dengan meja. Kedua, papan penyangga 
gelas samper air panas agar dibuat sedemikian rupa sehingga mudah digeser ke atas dan ke bawah. Ketiga, letak tiang besi penyangga selang B perlu digeser kearah depan sekitar 3 $\mathrm{cm}$ agar posisi selang $\mathrm{B}$ dan klem pemegangnya lebih lurus terhadap selang A dan mistarnya sehingga memudahkan pengukuran dan sekaligus mengurangi kemungkinan kesalahan. Keempat, ukuran lubang di meja tempat selang terjulur kebawah perlu diperkecil agar posisi selang A dan selang B bisa selalu sedekat mungkin sehingga memudahkan pengukuran dan sekaligus mengurangi kemungkinan kesalahan.

Hasil ujicoba penggunaan alat peraga tersebut dengan mahasiswa yang telah mengambil matakuliah tersebut diperoleh beberapa hal yang sebelumnya tidak dipertimbangkan: pertama, termometer alkohol yang diletakan pada gelas sampel air sebaiknya tidak diletakan dalam gelas dengan posisi yang kadang miring dan menyentuh dasar gelas yang lebih panas dari sisi-sisi lainya melainkan digantung pada tempat yang stabil. Hal ini untuk mempermudah pengukuran dan sekaligus menjadikan pengukuran suhu air menjadi stabil dan mengurangi kesalahan paralaks.

\section{Kesimpulan dan Saran}

Dari analisa data grafik diperoleh kesimpulan bahwa penggunaan termometer gas (hasil pengembangan) dengan menggunakan sampel gas dan air biasa maka menghasilkan titik potong grafik pada nilai $-351,8{ }^{\circ} \mathrm{C}$. Nilai tersebut tentu masih jauh dari nilai standar internasionalnya yaitu $\quad-273,15 \quad{ }^{\circ} \mathrm{C} \quad$ (Suhu terendah di alam ini). Namun demikian, sebagai alat peraga untuk menunjukan proses ekstrapolasi pengukuran suhu terendah di alam ini sudah dapat dilakukan dan mencukupi. Tidak diperolehnya hasil ukur yang sama dengan nilai standarnya tersebut kemungkinan masih ada kebocoran gas, kebocoran panas pada pipa kaca dan belum digunakannya gas yang mendekati sifat gas ideal (gas Helium) sehingga hasil ekstrapolasi yang peroleh masih jauh dari nilai literatur (eksperimen ini sangan membutuhkan kondisi yang sangat ideal).

Untuk mendapatkan hasil ekstrapolasi pengukuran suhu terendah yang lebih teliti perlu dilakukan (1) penggunaan air raksa pada selang (A dan B) dan (2) gas yang digunakan pada tabung labu adalah gas yang mendekati sifat gas ideal misalnya gas Helium. Pembuatan simulasi penggunaan termometer gas dengan program Flash juga perlu dilakukan agar mahasiswa yang akan menggunakan alat ini mencoba dulu dengan program simulasi komputer sehingga ketika menggunakan alat yang sebenarnya akan lebih mengerti dan mendapatkan hasil yang lebih baik.

\section{Daftar Pustaka}

Azhar, A. (2013). Media Pembelajaran. Jakarta : PT Raja Grafindo Persada.

Azhar, A. (2010). Media Pembelajaran dalam Pembelajaran Matematika SMP PPPG Matematika: Yogyakarta.

Betha, S. (2004). Pemrograman Web dengan $P H P$. Bandung: Informatika.

Widoyoko, E.P. (2009). Evaluasi Program Pembelajaran. Yogyakarta: Pustaka Belajar.

Hamalik, O. (1996). Kurikulum dan Pembelajaran. Jakarta: Bumi Aksara.

Hamalik, O. (2002). Psikologi Belajar Mengajar. Bandung: Sinar Baru Al Gensindo.

Hamzah, A. (1981). Media Pembelajaran Audio-visual. Jakarta : Gramedia Anggota IKAPI.

Herlina C. (1991). Penggunaan alat peraga Mikroskop Sebagai Upaya Meningkatkan Hasil Belajar Siswa Pada Mata Pelajaran IPA Di Kelas III SDN 3 Blambangan Umpu Waykanan. Lampung : Universitas Lampung.

Nasution (1985). Alat Peraga dalam Pembelajaran. Jakarta: Rineka Cipta.

Pujiati (2004). Penggunaan Alat Peraga Pembelajaran. Jakarta: Rajawali Pers.

Sudjana, N. (2009). Penilaian Hasil Proses Belajar Mengajar. Bandung: PT Remaja Rosdakarya.

Sugiyono, (2012). Metode Penelitian Kuantitatif Kualitatif dan $R \& D$. Bandung: Alfabeta.

Sukmadinata (2006). Metode Penelitian Pendidikan, Bandung: Remaja Rosdakarya.

Usman, H. dan Akbar, P.S. (2011). Metodologi Penelitian Sosial. Jakarta: Bumi Aksara

Wijaya dan Rusyan (1994). Kemampuan Dasar Guru dalam Proses Belajar Mengajar. Bandung: Remaja Rosdakarya. 
Zemansky, M.W. \& Dittmann, R.H. (1982).

Heat and Thermodynamics, Mc Graw Hill, Inc. 